This is an Accepted Manuscript of an article published by Taylor \& Francis Group in $\underline{\text { Children's }}$ Geographies on 17/07/2013, available online:

http://www.tandfonline.com/doi/pdf/10.1080/14733285.2013.817661

Published as:

Boyden, Jo and Neil Howard (2013) "Why does child trafficking policy need to be reformed? The moral economy of children's movement in Benin and Ethiopia", Children's Geographies 11(3): 354368. DOI: $10.1080 / 14733285.2013 .817661$

The article is reproduced in accordance with the self-archiving policies of Taylor \& Francis Group. 


\title{
Why does child trafficking policy need to be reformed? The moral economy of children's movement in Benin and Ethiopia
}

By Jo Boyden and Neil Howard, University of Oxford

\begin{abstract}
This article challenges policy discourses that frame children's independent movement as intrinsically exploitative and threatening to their development. Drawing on research with children and adults in Benin and Ethiopia, two countries caught up in current efforts to eradicate child migration and the trafficking with which it has become associated, the article critiques assumptions about children's vulnerability and physical dependence and contests the idea that appropriate childhood is necessarily fixed spatially within stable family structures. It thus situates children's migration within socio-cultural and economic contexts and suggests that it should be understood as part of a moral economy that confounds simplistic paradigms that conflate migration with trafficking. Policy suggestions are offered for how best to secure children's well-being through acknowledgement of the important relationship between mobility and child maturation.
\end{abstract}

\section{KEYWORDS}

Child independent migration, Benin, Ethiopia, trafficking

\section{INTRODUCTION}

Few topics are afforded greater attention in contemporary policy debates than that of human mobility. In the past six years alone, the UN has established a Global Commission on International Migration to examine the phenomenon of human movement, convened the High-level Dialogue on International Migration and Development to discuss the links between movement and socio-economic change, and 
set up the Geneva Migration Group with the International Organization for Migration, to explore how to manage and share information about migration ${ }^{1}$. These initiatives echo the concern among nation-state officials about un-sanctioned international migration which has, in turn, been associated with a spate of migration-restricting measures and an outburst of anti-migration rhetoric (Kempadoo 2005, Huysmans 2006).

While migration in general attracts significant attention, the independent movement of minors has begun to cause particular disquiet, with migration governmentalities increasingly gaining hold over how child and family life are regulated in many parts of the world (Hashim 2003, Huijsmans 2006, 2011, O'Connell Davidson and Farrow 2007, Whitehead et al. 2007). Institutions across a variety of contexts have come to understand a child's departure from the parental home (whether for care, learning, or labour) as a child protection violation, seemingly representing an involuntary act that stems from adult negligence and exploitation, and leading inexorably to harm for children, their families and their communities. Child movement has thus increasingly become conflated with trafficking, a conceptual confusion that has significant consequences for policy.

Based on primary data from Benin and Ethiopia, this article explores the social and economic motivations for young people's independent movement and its implications for them. The article accepts the policy proposition that poverty is an important context for children's mobility and notes that not all movement is positive for those concerned. Nevertheless, it finds no evidence that children's movement reflects the horror stories prevalent within the trafficking narrative. Quite the opposite, it reasons that young people's migratory practices are embedded within powerful moral economies which at one and the same time bolster households against poverty and risk and facilitate the development of important skills among the young, thereby ensuring their transition to adulthood. It therefore calls for greater recognition of the historical and contemporary importance of children's independent migration to domestic economies, to children's

\footnotetext{
${ }^{1}$ See http://www.un-ngls.org/orf/international migration.htm for details. Accessed 15/1/11.
} 
development and social integration and to broader cultural transformation. By drawing on two contrasting and complimentary datasets from countries previously underexamined in the critical literature around child mobility, the article seeks to make a unique contribution to this emerging field.

\section{METHODOLOGY}

The Benin data derive from doctoral research with male adolescents and youth who are currently or were formerly involved in labour migration to the artisanal mines of Abeokuta in Western Nigeria and surrounding areas, and adolescent male migrants working as blacksmiths and itinerant salesmen in Cotonou. The research involved 14 months of multi-sited ethnographic fieldwork, during which participant observation was undertaken with individuals and institutions active in forming and implementing antitrafficking policy throughout Benin and interviews were conducted with more than 300 respondents within these institutions and in villages with high concentrations of young migrants.

Most of the young migrant interviewees were from the poor, principally agricultural, Zou Department, which is perceived to be the hub of child labour, trafficking and exploitation in Benin. The research with migrants was conducted in four case study villages, two from each of two communes-Zakpota and Zogbodomey-two with flagship 'village child protection committees' and two without. Diverse methods were used, including principally open-ended individual and group interviews, the focus of which was on how people see their life-worlds, how they experience and view (hazardous) youth work and movement, what they think about current anti-trafficking interventions, and how they would like to see those interventions change. 
The Ethiopia data are from Young Lives², a mixed-methods study of childhood poverty that is tracking 3,000 Ethiopian boys and girls in two cohorts (one born around 1994 and the second, 2001) over a 15-year period. The sample households are located in 20 sentinel sites distributed over the regions of Amhara, Oromia, Southern Nations, Nationalities and People's Region, Tigray, and the capital, Addis Ababa. The sites were chosen purposively to reflect rural and urban location, diversity in ethnicity and social and economic circumstances, while households with children in the appropriate age groups were selected randomly.

So far, Young Lives has gathered 3 rounds of survey data from the full sample and 3 rounds of qualitative data from a sub-sample of 104 children from both cohorts. The sub-sample is drawn from 5 sites, one for each of the regions from which the wider sample of sites was drawn, plus Addis Ababa. The survey consists of three questionnaires, administered separately to the children, their caregivers and community members. The qualitative research entails individual interviews, focus groups, wellbeing exercises and a range of other methods, applied with the same respondents at each round and concentrates on children's lived experiences and the circumstances of their daily lives. Although the study does not concentrate specifically on independent child migration, migrant families and children are tracked whenever possible so that their circumstances and outcomes can be compared with those of children and households that remain at their place of origin. At the same time, the case studies of the children in the qualitative research include information on their migration experiences and it is these data that form the basis of the current article.

\section{POLICY ASSUMPTIONS}

\footnotetext{
2 Young Lives is core-funded by the UK Department for International Development (DFID) and the Netherlands Ministry of Foreign Affairs (DGIS) for the benefit of developing countries, with sub-studies funded by The Bernard van Leer Foundation, the International Development Research Centre (IDRC), the Oak Foundation and UNICEF.
} 
Global policy asserts that migrant children are driven from their homes through 'poverty, harmful social practices, or the breakdown of societal values' (Heissler forthcoming) and in this way, mobile, homeless and nomadic children have become a site of widespread institutional moral panics (Hashim 2003, Ní Laoire et al 2010). This rhetoric is intuitive rather than evidential and rests on three sets of ideas, the first concerning the governance of populations, the second, children and their development, and the third, children's movement. Starting with the first, governments everywhere imagine people on the move to be a threat to national sovereignty and security and many deploy sedentarising measures, such as stringent restrictions on crossing borders and permissions to migrate, as a means of containment (De Haan 1999, Rain 1999, Scalletaris 2007, Huijsmans 2011, also citing Sheller and Urry, 2006: 208). Because they are often left behind, or thought to move as members of families, children's movement only became a cause for concern recently, when it became apparent that many young people migrate alone.

The perception that children's independent migration is intrinsically detrimental rests on the second set of ideas, which emphasise seemingly universal features of childhood, a life phase that is distinguished by chronological criteria, with age 18 the upper limit (discussed by, for example, Huijsmans 2006, 2008, Whitehead et al. 2007). Young people within this chronological category are essentialised as inherently vulnerable and hence at risk in contexts of uncertainty or change (UNICEF 2011), their healthy development depending on the continuity of care and protection by familial adults and, where this fails, the state (Boyden and Mann 2005). This model gives prominence to the allegedly unique psychological and emotional attachments laid down through the mother-infant bond. It also emphasises the importance of secure, nucleated, family structures. The most influential formulation of this protective care regime within policy is the United Nations Convention on the Rights of the Child (CRC), which provides the bedrock upon which virtually all other international child-focused treaties build.

Pessimistic assessments of child migration as family breakdown are compounded by the third set of ideas, which holds that independent movement is fundamentally 
dangerous for the young. Seemingly, by leaving the protective domestic sphere, crucial familial ties are severed and young people become locked into inappropriate or abusive relations with strangers; hence the frequent conflation of child migration with child trafficking. Described by the International Labour Organisation (ILO) as 'a global problem' that 'strips children of their childhood' (Boonpala and Kane 2001:1), trafficking has now become a chief concern for child protection professionals internationally (see Dottridge 2007, De Lange 2007). This discourse tends to distinguish between the trafficking of younger children into inappropriate forms of care and the trafficking of older children into exploitative labour.

In the 'Trafficking Protocol'3 of the UN Convention on Transnational Organised Crime, the crime of trafficking constitutes any involvement in the process of coerced movement for the purposes of exploitation. Crucially, the Protocol states that a minor's consent to exploitation is irrelevant in determining situations of trafficking and it does not specify what constitutes exploitation (beyond sexual exploitation, forced labour and slavery). Instead, policy makers rely on the ILO's anti-child labour framework, which prohibits any economic activity under the minimum age of employment and urges states to proscribe sex work, slavery and other 'harmful' forms of work by economic sector. Consequently, whenever a particular sector is judged exploitative or unsuitable for children, all migrant children involved in that sector are defined as victims of trafficking. In some countries, laws have thus been passed to protect children by pre-emptively preventing their movement. Prominent local figures and committees are often tasked with 'sensitising' the population to the dangers of child (labour) mobility and convincing the young to stay at home (Dottridge 2007).

Human trafficking exploded as an issue in Benin in 2001 with the discovery that the Etireno, a Nigerian trawler, was being used by people-smugglers to illegally transport West African children to Gabon. After a complex series of events involving law

\footnotetext{
${ }^{3}$ United Nations (UN) (2000), 'Protocol to Prevent, Suppress and Punish Trafficking in Persons, Especially Women and Children, Supplementing the United Nations Convention Against Transnational Organised Crime', New York: UN General Assembly.
} 
enforcement and diplomatic pressure from various countries, the ship and its passengers were left stranded at sea, prompting local child protection organizations to raise the alarm and the world's media to claim evidence of a modern-day slave trade 4 . Benin was thereby identified as an 'epicentre' of the traffic in children, and the government responded by ratifying the Trafficking Protocol, facilitating an influx of antitrafficking funds, and establishing various anti- child trafficking initiatives.

The dominant institutional narrative in Benin holds that trafficking is a major problem in the country and involves children being forced away from home and into exploitative work, largely through grinding poverty, the corruption of traditional practices and parental irresponsibility (Howard 2008). Anti-trafficking measures include the strengthening of border patrols, enhanced cooperation with Nigeria on trans-border surveillance, widespread anti-work and anti-movement 'sensitisation' or 'responsibilisation' campaigns, the promulgation of the Law Regulating the Movement of Minors and Suppressing the Traffic in Children and the establishment of Village Vigilance Committees charged with preventing children's labour migration at the village level.

The policy discourse in Ethiopia is less strident than in Benin, although the government's recent Growth and Transformation Plan included a target for reducing illegal child migration and trafficking (MOFED 2010). The Ministry of Women, Children and Youth Affairs stresses the importance of the family environment to children's welfare and attributes child migration and the separation of children from their families to familial failure (Gebre 2010, Gedlu 2010). Common causes are said to include low levels of awareness, divorce, addiction, poverty, and/or parents having more offspring than they can support. Currently, international migration (including in the form of adoption) is a key governmental policy concern, the perception being that migrant or adopted children risk an identity crisis and associated psychological difficulties. Government responses consist mainly in efforts to encourage local adoption and

${ }^{4}$ The Independent, 18 April 2001, available at:

http://www.independent.co.uk/news/world/africa/mystery-of-missing-children-as- slave-ship-docks-681766.html. 
community care as more acceptable alternatives. There is also a concern with children who live in nomadic areas and with migration for work to Arab countries, although the latter is believed to involve young women rather than minors. Non-governmental organizations, on the other hand, are more focused on child trafficking and children migrating to towns to become domestic workers (Assazenew 2010, Tegegne and Asres 2010).

\section{Academic challenges}

There is a significant body of empirical and theoretical work within diverse disciplines which brings into doubt many of the assumptions underpinning anti-child trafficking and migration policies. Recent research kicks back against the tendency of earlier studies to treat children as appendages in migratory processes (Heissler 2010, Whitehead et al. 2007) and questions the narrative of migration-as-trafficking (Heissler forthcoming, Thorsen 2007, Hashim 2005), arguing that many migrant experiences are not at all detrimental to the young (Crivello 2008, De Lange 2007, Hashim and Thorsen 2011, Howard 2008, Leinaweaver 2007, 2008, Punch 2007, Whitehead et al. 2007).

At the same time, there are many who challenge the essentialising ideas around childhood as a universal life phase characterised by residential fixity and domestication (Ní Laoire et a.l 2010), some pointing to the coherence between childhood learning, work and movement in different parts of the world (Crivello, 2008, Heissler 2009, Huijsmans 2008, Leinaweaver 2008). On this basis, the validity of applying arbitrary minimum age criteria to childhood, whether it be an enforced threshold for paid work (Bourdillon et al. 2011) or independent migration (Huijsmans 2011), is disputed. Research with children in diverse contexts highlights the significance of social over chronological age, providing extensive evidence that young people commonly assume important reproductive and productive roles well before reaching globalised chronological thresholds (Bourdillon et al. 2011, Dobson 2009, Hashim and Thorsen 2011). It is now well established that essentialising discourses that depict young migrants as intrinsically vulnerable are erroneous, for many turn out to be highly agentive, (Ansell, 2005, 2009, Ansell and van Blerk (2004), Hashim and Thorsen 2011, 
Heissler forthcoming, Huijsmans 2011, Punch 2007), including in contexts of extreme adversity (Boyden and de Berry 2004), and many deploy independent migration to enhance economic and social opportunities (Crivello 2008, Dobson 2009, Punch 2007).

The assumption that children are highly prone to being exploited by unscrupulous traffickers when they migrate is also challenged. Heissler (2009), for example, shows that although labour migrant girls in Bangladesh often move with adults, these adults are not traffickers but part of established and protective social networks. Similarly, the attachments and bonds that are imputed to be so central to children's development and thus so integral to the anti-movement discourse (Hashim 2003, Whitehead et al. 2007) are increasingly being understood as themselves contextual (Alber 2003, Mann 2001). Indeed, many contend that spatial separation does not lead inevitably to the breaking of bonds, pointing to the spatially dispersed nature of families and to close familial ties that are very often sustained across households and communities (Ansell and van Blerk 2004, Van Vleet 2008, Verhoef 2005, Walmsley 2008, Whitehead et al. 2007). Studies of child-rearing practices highlight the frequency of extra-parental guardianship, (Hashim and Thorsen 2011), such as through child fosterage (Goody 1982), or sibling care-giving (Weisner \& Gallimore 1977), which produce children characterized both by 'the diffusion of affect' and 'attachment to community' (Mann 2001), and for whom movement away from parents can be understood less as a breach of the developmental process and more as its direct articulation (Ansell and van Blerk 2007, Howard 2008, Whitehead et al. 2007).

\section{CHILDREN'S MOBILITY IN BENIN AND ETHIOPIA}

Current evidence suggests that in many environments of scarcity where familial ties are dispersed spatially, the movement of young people is not only customary but also, very often, constructive. Here we examine the evidence from Benin and Ethiopia and outline some of the reasons why this might be the case. Focusing on both intra-familial relocation and extra-familial migration, we start by outlining the economic imperative 
underpinning the mobility of the young. Our core argument is that young people's movement is embedded within a nexus of practices that are vital to sustaining intergenerational regimes of survival, learning, social care and work and in this way serves both individual and collective interests.

\section{The Economic Imperative}

By calling for a blanket ban on the independent movement of young people under age 18 , global policy ignores the social and economic context of migratory practices. When young people leave home it can enable households to reduce economic risk, enhance their income and protect their consumption, as well as ensure provision for family members that cannot be catered for within the natal home.

Ethiopia has experienced consistent economic growth and advances in service access in recent years. Even so, it remains one of the poorest countries in the world and Young Lives households are exposed to high levels of food insecurity and environmental and economic risk, especially in rural areas, where most depend on rain-fed subsistence agriculture (Woldehanna 2010, Woldehanna et al. 2011). The poorest families in the sample report the greatest number of risks, with rural caregivers citing death of livestock, drought and crop failure as most affecting children, and urban caregivers citing loss of employment or income and food price increases (Boyden 2009). The children, though, tend to be far more focused on the effects of illness within the household, which very often increases their work burden, threatens schooling and is a motive for leaving home.

Nevertheless, despite widespread poverty and economic insecurity among sample households in Ethiopia, there is less evidence than in Benin of independent extrafamilial migration, whether within the country, or to neighbouring countries, possibly because of limited opportunities, government restrictions on migration, or the age and gender of the children. Far more common, is intra-familial relocation. Few Ethiopian households are autonomous economically or socially and most rely on an extended network of kin and affines that may stretch across several households and 
communities. These ties provide a vital mechanism for the care, training and work of the young, co-residence of parents and children not being a pivotal feature of domestic life.

By approximately age eight, a full 34.5 percent of the younger cohort and by about age fifteen, 52 percent of the older cohort were living apart from at least one of their parents, more often the father than the mother (Crivello and Chuta forthcoming). At the same time, 20 percent of the older cohort sample had been orphaned of at least one parent (Young Lives 2009). Nonetheless, despite high levels of orphaning and household dispersal, the extended family remains central to the care of the young, for only 1.4 percent of the older ones and 0.3 percent of the younger ones were living with non-kin (Crivello and Chuta, forthcoming). The majority of paternal orphans live with their biological mothers, whereas arrangements for maternal orphans are extremely diverse, grandparents being the most common option. Many of the children left home following the death of one or both parents, or parental separation.

Benin is also one of the world's poorest countries, with much of the population living on less than a dollar a day and survival dependent on subsistence or poorly remunerated farming activities. Adolescent male migrants and their communities in Benin thus frequently cited lack of resources and opportunities in their home environment as the major reason for moving away and the majority of the young respondents who were not living with their parents had come from poor households that had faced some kind of unexpected hardship. When Yomana's ${ }^{5}$ father died, for example, both of his older sisters migrated to Cotonou to live with relatives. Similarly, Jeg, a young man who had recently returned from a decade of working in Côte d'Ivoire, left Zakpota because his father's long illness and ultimate death had resulted in his family's destitution and inability to care for him or his sister.

Charley, who is chief of Zelele and Chair of the state's local Anti-trafficking Committee, pointed out that in his village, 'there is poverty, and where there is poverty, people

\footnotetext{
${ }^{5}$ Names of people and local places have been changed to protect the identity of research respondents in Benin and Ethiopia.
} 
leave'. Winston deplored the dwindling of fish stock in the lake on which his community had depended for generations, and explained that this had forced many young people to move. Likewise, Freddy, a former child migrant from the West of the country, reasoned that child mobility is 'a question of means - poor people...are the ones who send their children away', while a man from Tenga said,

There is nothing in the village, there is no work. Parents are obliged to let their kids go and when kids decide themselves to leave, parents are obliged to accept. When they go, kids at least make some money, they at least send some back to us. We understand the NGOs' message, but we can't eat their words can we? (Tenga Village, Zogbodomey, 16/4/10).

Children interviewed in Zakpota paralleled precisely these understandings:

Have some of you ever been away to do summer work? Yes, every single one of us!!! That is what allows us to continue at school!! You can go to Nigeria or Savè and earn 30k or 40k in a summer. What work do you do? In Savè, it is the land. In Nigeria, it is the land but also the mines. How is it? It's hard but it's ok. Do the small children go as well? Yes, from 11 onwards (Sehere Village, 14/5/10).

In resource-poor environments such as in Benin and Ethiopia, poverty and crisis provide a strong economic imperative for child relocation within or outside the extended family. Families move their children in response to localised economic shocks, as well as to maximise household and family production and enable accumulation for essential outgoings such as school expenses. They are both reactive and pro-active, as is necessary in such a context. Nevertheless, though economic hardship provides a compelling context for many young people to move out of their natal home, they seldom move simply out of economic necessity or following a crisis. Indeed, most such movement is shaped not merely by material want, but by a complex interplay of material and moral considerations that accord with powerful cultural repertoires around childrearing and care. 
Children have greater need of learning than do adults and young ones tend to have far greater requirement of care and also, until they reach puberty at least, they tend to be less tied to gender roles and have fewer dependents than adults; thus, when prerequisites of child training, care and labour cannot be met within the natal home, movement to another household is regarded as both natural and auspicious. For example, of the ten children and young people in one household in the Beninese sample, only two were the biological offspring of the household head, the others having relocated for school or work. In Zelele, Adam had four young people living with him, all of whom were the children of his brother, while his own daughter had just returned from Lome, where she had spent two years staying with her aunt. When one man was asked about how he would know that his daughter would be treated well in her uncle's home in Gabon, he replied simply: 'She's not going away...she's going to be with my brother and sister, my own flesh and blood, so she will be treated just as if she were here.'

\section{Migration and inter-generational mutuality}

Global policy assumes children to be dependent on adults, and yet one of the key features of care and labour regimes in poor communities is the propensity for all individuals to work according to their capacity and thus for a high degree of interdependence between generations to be the norm. So, in 2009 more than 90 percent of the 8-year-olds and 98 percent of the 15-year-olds in the Young Lives sample in Ethiopia were involved in some kind of work, paid or unpaid (Woldehanna et al. 2011). Tasks are usually assigned in line with gender and maturity, though the birth order and gender composition of the sibling group can alter this (Boyden 2009, Heissler and Porter forthcoming). Boys, poor and rural children have higher participation rates in unpaid family activities than urban children, girls and non-poor children, respectively (Woldehanna et al. 2011). Caring for siblings and household chores take up the highest share of children's (particularly girls') time, especially in rural areas, followed by unpaid work within the family, such as farming and cattle herding. The time children spend working overall is greater in rural than urban areas and the older ones are substantially involved in working for pay. 
With young people contributing vital reproductive and productive labour and/or remitted income to households, it is perhaps unsurprising to find that considerable importance is attached to their developing the social and life skills necessary to facilitate such roles, while child idleness is also disparaged (Boyden 2009). These skills generally accord with the child's maturity and gendered and generational expectations (Abebe and Kjørholt 2009, Howard 2008) and are often best provided for through intra-familial relocation. In Benin, children in early or middle childhood are therefore very often sent to caregivers who are perceived most likely to ensure that they develop valued social and life skills. Where an uncle is more authoritative than a father, for example, an errant or lazy child might be sent to him for guidance, while if an aunt has more schooling, a studious child with a bright academic future might be sent to live under her watch. Women in Zelele explained that, in the event of having nothing to do, it would be advisable for a young male to leave his home and find work in a related household or elsewhere, because 'he needs to learn how to contribute'. The social (and indeed practical) importance of learning such a lesson was underlined by the claim that, if he did not, 'he would end up becoming a thief' - a figure universally reviled in the community for taking without giving. As such, it was concluded, 'it is better for both the child and the community for him to depart'. The importance of children learning the attributes needed to contribute their labour power is thus clearly apparent within this understanding of what it means to be an active member of the community.

Children's learning and economic security aside, one of the other major attributes of young people's intra-familial relocation is its contribution to the host household, boys and girls commonly moving in with relatives to ensure both their own protection and learning and to augment the gendered labour of households that have labour shortages. In many cases, the motivation is social care for the elderly. For example, it was decided that Buzunesh, (then aged about nine) a paternal orphan from Oromiya, in Ethiopia, should move in with her maternal grandmother when she fell sick. Buzunesh's mother has three young children to look after, so it was reasoned that Buzunesh was the only family member suited to caring for the old woman. The grandmother explained the arrangement as an expression of the close tie she has with her daughter, outlining how 
it works: "Before, she [Buzunesh] used to come and go, but now she has come to stay with me. So, her mother decided that she shall stay here and take care of me until I die. She takes care of me and I take care of her schooling." In her new home, Buzunesh makes the coffee, cooks, collects firewood, fetches water and washes the clothes.

Respect for the reciprocal nature of inter-generational claims and duties is key to the success of young people's intra-familial relocation. This can be seen from the case of Kebegna, also from Oromiya, who, at age six was given over to the care of a widowed aunt when her son left home to join the military. Kebegna assumed his aunt's dead husband's name and in return for food and lodging, herded her cattle, fetched water and firewood and cleaned the floor. But he was made to work long hours, sometimes without food, and had to drop out of school twice because of his workload. He was also denied medical attention when he became ill and finally, on returning home from the army, the aunt's son started mistreating him. Eventually, after a couple of years, Kebegna decided to return home and resumed use of his father's name. When asked why he had left his aunt, he emphasised how she had stopped communicating with him (using local idioms such as, 'because she left me' and 'she was not ordering me'), this in his view being evidence that she 'hated' him. Thus, from Kebegna's case it is evident that intra-familial relocation is about a great deal more than the mere material exigencies of crisis and, far from denoting a rupture in emotional bonds, as implied by the policy discourse, is rooted in particular expectations of affect linked to ideas about the appropriate nurture of the young.

\section{Migration and social transitions}

So far, we have outlined the part played by children's movement in sustaining household livelihoods, kinship mutuality and personal development in precarious subsistence, or near-subsistence, economies. However, by accentuating its role in fulfilling the status quo, we do not intend to paint a static picture, for the moral economy of child mobility is in practice exceedingly dynamic. Very often, young people's mobility represents a vehicle for both individual and collective ambition, as well as being a vector for personal transition and familial transformation, as should be evident from some of 
the cases already cited above. For example, the impressive expansion in primary school facilities in Ethiopia in recent years has been matched by rising expectations around education, such that many families and children (boys and girls alike) perceive schooling as the single most important path towards a better future. However, since many rural communities do not have secondary schools, continuing education has emerged as one of the most important reasons why many children, especially boys, in the Young Lives sample leave the natal home (Young Lives 2009b: 2, see also Abebe 2008).

Similarly, even though in Benin 'poverty' is nearly always and everywhere the immediate response to the question 'why do young people leave the village?' deeper exploration commonly reveals the pro-active quest for economic opportunity and the advancement this brings to be a second important motive. So, when a group of young respondents in one village were asked, to their amusement, whether 'poverty' meant 'starvation', whether people remaining 'would go without food?' a resounding 'no' was the answer. In another conversation, a village chief and his friend explained, 'People don't die of hunger here. Even if you do nothing, you will be fed.' Similarly, Winston, the father of two adolescent migrants, declared, 'When there are no fish, people don't starve - it's not like that, people wouldn't let you starve - it's just that there's no money.' As a group of 15 teenagers in Tenga explained, when people say 'ya', the Fon word for 'poverty', what they mean is 'no money, no jobs, no opportunity'.

Frequently, the fulfilment of young people's migratory aspirations is as much about serving the wider group as about individual interests. Hence, one young Beninese returnee from the Abeokuta mines in Nigeria cited roofing his father's house as one ambition, while others talked about remitting income. Parents, grandparents and other adults may make major sacrifices to enable the young to migrate for schooling, generally in the full expectation that the wider family will benefit from improved income and gain a foothold in an urban centre. In this sense, aspirations around the mobility of the young are at the same time transforming expectations of inter-generational mutuality; no longer just one household resource among many others, young people are 
fast becoming the main locus of advancement of the kin group. Fatuma, in Ethiopia, is an example of this. Having lost her father to illness, her mother's recent descent into illhealth has convinced her she must leave the country to get a job and help her mother overcome poverty.

Extra-familial movement of the young often takes place at marriage and therefore facilitates their transition into adulthood and progression through the life course. In Ethiopia, girls generally marry at around puberty, whereas boys normally wait until they have accumulated sufficient resources to cover the cost of bride-price and/or establish a new household (Boyden et al. forthcoming). Marriages are usually arranged by the couple's families, this securing the social heritage of the kin group and future support for the newly-weds and their offspring. However, elopement is becoming increasingly common throughout Ethiopia, with significant implications for both inter-generational ties and young people's transitions. This practice is perceived by many as undermining familial relations and traditional family values, not least because it is often associated with a reduced bride price and results in legal disputes. In these cases transitions to adulthood are not always entirely successful since ties between the couple and their kin may be severed, whether temporarily or permanently, occasionally leading to destitution among younger generations (Boyden et al. forthcoming).

In Benin, being 'considered' as adults worthy of respect is a crucial goal, and means being respected, a person of importance, having made good and being able to demonstrate this fact to others. Migrating away for work is very often viewed as an effective path to achieve this status, as when young migrant males return home with motorbikes, money or wives. Equally, the repeated temporary migration to work summer jobs on farms that accompanies the onset of adolescence in Southern Benin represents a vehicle for young boys to access, and keep, their own money. Whereas working their fathers' farms may be an important familial contribution which they all value, temporarily migrating for wage labour, even when they remit a portion of their wages to their parents (as all claim they do), allows adolescent boys to begin to articulate their own independence, since they hold on to a share of what they earn (Howard 2008). It can 
also be the process of migration itself, rather than simply the outcome, which gives rise to such a transition. A local social worker, who deplored the risks associated with migration, explained that one boy was wedded to the idea of movement because 'it was through suffering elsewhere' that he could 'become a man'.

\section{Migration as coercion?}

We have made the case that global anti- child trafficking/ child migration policy emphasises the exploitative nature of young people's movement and holds that, as minors, children's choices are irrelevant in this process. This paradigm cites a toxic combination of family poverty, irresponsibility, and mistreatment by traffickers, as causal in the apparent wave of human misery encapsulated in child mobility. Since poverty and adversity are in reality often common impulses in the movement of the young in Benin and Ethiopia, and since many boys and girls do have little say about moving away from home, the policy emphasis on the involuntary nature of mobility may appear to have some validity. The emphasis on widespread coercion, suffering and abuse seem misplaced, however.

On this basis, we would argue - as have others - that a true understanding of the place of migration in young people's lives requires their conceptualisation as social agents, for this makes possible an assessment of whether or not they are able to exercise meaningful choice. On this topic, there is great diversity in our findings, although several general trends do emerge. While some young people undoubtedly do use their own judgment, the younger ones and girls are, by and large, less able to assert their preferences than are teenagers and boys (see also Abebe and Kjørholt 2009). In Southern Benin, this is consistent with norms whereby younger children and girls tend to have their migration settled on by adults (usually involving placement in domestic work within or outside the kin-group), while adolescent boys are expected to earn a wage and so frequently migrate in order to do so.

In Ethiopia, choice is gendered and girls more often than boys seem to be confronted by incompatible goals in relation to intergenerational care, learning and labour. While many 
families are supportive of their daughters migrating to urban centres to take advantage of opportunities available there, social expectations of girls are such that collective interests often to trump individual ambition. This is apparent in the case of 12-year-old Haymanot from Tigray. Her father having abandoned the family and her sister having migrated to the regional capital in search of a job, Haymanot also moved out of her home in order to go to school. She moved to a local town where she lived with an aunt for three years. However, her mother fell ill, resulting in Haymanot leaving school and returning home. Haymanot now looks after both her mother and her younger brother, undertaking all of the household chores, weeding the family's fields, collecting fire wood, and working for pay in a government social protection programme and a stone-crushing plant. Haymanot expressed deep disappointment that the family's current circumstances had so undermined her ambitions.

Similarly, even though early marriage is usually framed by parents as protective of girls' futures as adults, for many of the adolescents concerned it hinges more on a sense of duty or compulsion (Boyden et al. forthcoming). The experience of Sefinesh's mother is one of the more extreme examples from the Young Lives study. She was in her early teens when her father decided that she must leave home and school to get married. Sefinesh's mother was very unhappy in the marriage and after giving birth to a baby girl, sought a divorce, returned home and went back to school. But her father insisted she re-marry and again removed her from school. This time, only a month into the marriage and unaware that she was already pregnant with Sefinesh, she ran away from her husband to return to her parents' home and to school. Forcibly removed from school and remarried a third time, she became pregnant once more, although this baby was stillborn. This marriage also failed and eventually, in despair, Sefinesh's mother migrated to Addis Ababa for good, leaving her daughters in the care of their grandparents. The father has now changed his views radically and has no plans to marry Sefinesh off and, indeed, is encouraging her to remain at school for as long as possible.

Circumstances are very different for the adolescent male respondents in Benin, most of 
whom made their own decisions to move, with or without parental consent, some of whom simply chancing their luck. Didier, for example, decided to migrate with a friend to Cotonou to become a blacksmith's apprentice when his parents told him they could no longer afford his school fees. Similarly, having failed his latest year at school at age 14, Christophe determined that it was time to get a job. His father acceded to his wishes and helped him secure an apprenticeship with the Cotonou blacksmith who employs Didier. Ethan and a group of friends from his village, on the other hand, travelled to Cotonou to become ambulant scratch-card sellers after a young returnee migrant passed the word around that good money could be earned this way.

Such differences in the degree of personal volition involved in young people's migratory practices highlight a further difficulty with a ban on all child migration, which cannot realistically cater for the intricacy of moral and material factors that are brought to bear in assessments about what best serves whose interests. Clearly some children are not consulted when it is decided that they should move and not all are happy with migratory arrangements made on their behalf, and yet there is little evidence of parents acting irresponsibly and it would seem that in some cases, staying put could be more detrimental to their wellbeing.

\section{CONCLUSION}

In the modern world, policy can fundamentally impact children's lives, for better or for worse; hence, the assumptions and approach of policy are absolutely central to the wellbeing of the young. Based on our evidence from Benin and Ethiopia, we have argued that policy around children's migration and trafficking involves a number of false assumptions which bring into doubt the appropriateness of abolitionist measures that criminalise these activities. Thus, while young people (especially girls and younger children) do not always have a choice and departure from the home can have detrimental personal outcomes, this does not necessarily imply irresponsible parenting, exploitation by intermediaries, breakdown of familial ties, or damage to individual prospects. In this, our findings concur with studies by others (eg, Ansell and van Blerk 
2004, Crivello 2008, Dobson 2009, Hashim and Thorsen 2011, Punch 2007, Whitehead et al. 2007) which highlight the many constructive aspects of independent child migration for the young, their families and communities. Our principal assertion is that child mobility in Ethiopia and Benin has long been essential to the moral economy of inter-generational mutuality in contexts of material scarcity and uncertainty.

Children's movement needs to be understood in historical and economic-moral contexts in which households have always depended on the labour of all active members, and childhoods were never fixed spatially within stable, nucleated family structures. This involves consideration of the ways in which different child-rearing objectives and practices may prime boys and girls in the early development of specific skills and behaviours that will be advantageous to them in their daily lives, both practically in terms of meeting their current and future needs and those of their families, and socially and spiritually in terms of being morally worthy (Mann 2001). As well, it needs to be understood that when young people leave home they are not necessarily leaving the supportive familial network that transcends that home, nor are they breaking ties central to their well-being. Far from physical departure leading to rupture, boys and girls frequently depart both within and because of those bonds, themselves more diffuse and less spatially-constrained than is generally assumed by policy makers. Generations and households are interdependent, learning comprises important pro-social skills, and care-giving is multiple. Life strategies therefore necessarily involve-and are indeed constituted by-navigating a path between all of the above. Migration is sometimes a vital part of that path.

Rather than attack the moral integrity of families and essentialise children as victims, policy that wishes to promote the well-being of migrant and potentially migrant young people should reconfigure itself along lines that take into account children's sociocultural and economic realities, including their gendered roles and responsibilities. Addressing the macro-structural economic underpinnings of poverty and exploitation is of course a sine qua non. But this can be accompanied by micro measures, such as the introduction of life-skills training in schools, the establishment of referral systems or 
support groups in migrant destination cities, the expansion of social security and social protection measures and labour inspectorates that ensure the safety of migrant work, as opposed to preventing that work from taking place. Given that access to schooling is often a major incentive for migration, attention is needed also to expanding quality and relevant school education in rural areas. Only when such forward-thinking and nuanced measures are enacted will policy-makers genuinely be able to claim that their efforts are promoting the best interests of migrant children.

\section{REFERENCES}

Abebe, T, (2008) Trapped between Disparate Worlds? The Livelihoods, Socialisation and School Contexts of Rural Children in Ethiopia, Childhoods Today Vol 2, Issue 1.

Abebe, T. and A.T. Kjørholt (2009) Social Actors and Victims of Exploitation: Working Children in the Cash Economy of Ethiopia's South, Childhood 16 (2): 175-194.

Alber, E. (2003) Denying Biological Parenthood: Fosterage in Northern Benin, Ethnos 68(4): 487-506.

Ansell, N. (2005) Children, Youth and Development, London, New York: Routledge.

Ansell, N. (2009) Childhood and the Politics of Scale: Descaling Children's Geographies? Progress in Human Geography 33(2): 190-209.

Ansell N. and van Blerk L. (2004) Children's migration as a Household/Family Strategy: Coping with AIDS in Malawi and Lesotho, Journal of Southern African Studies 30(3) 673-690.

Ansell, N. and van Blerk, L., (2007) Caregiving in the context of HIV/AIDS in Southern Africa: complex Strategies for Care, Journal of International Development 19 (7): 86588. 
Assazenew, A. (2010) 'Causes of Child Trafficking from Cheha Woreda to Addis Ababa', in Children on the Move in Ethiopia. Papers presented for ESSSWA Seminar Series on Children, Addis Abababa, March.

Boonpala, P. and Kane, J. (2001) Le Trafic des Enfants dans le Monde Problème et Réponses, Geneva: BIT.

Bourdillon, M., Levison, D., Myers, W. and White, B. (2011). Rights and Wrongs of Children's Work, New Jersey: Rutgers University Press.

Boyden, J. (2009) Risk and Capability in the Context of Adversity: Children's Contributions to Household Livelihoods in Ethiopia, Children, Youth and Environments, 19:2.

Boyden, J. and de Berry, J. (2004) (eds) Children and Youth on the Front Line: Ethnography, Armed Conflict and Displacement. Oxford and New York: Berghahn Books

Boyden, J. and Mann, G. (2005) Children's Risk, Resilience and Coping in Extreme Situations. In Michael Ungar (ed) Pathways to Resilience. Thousand Oaks, London New Delhi: Sage Publications, pp 3-25.

Boyden, J., Pankhurst, A. and Tafere, Y. (forthcoming) 'Harmful Traditional Practices and Child Protection: Contested Understandings and Practices of Female Early Marriage and Female Genital Cutting in Ethiopia', Development in Practice no.3, May.

Crivello, G. (2008) "Becoming somebody": Youth transitions through education and migration - evidence from Young Lives, Peru, Oxford. http://www.childmigration.net/YL Crivello 09 . Accessed 27.10.11 
Crivello, G. and Chuta, N. (Forthcoming) "I look for help from others when I can't do things on my own": sources of support for orphaned and vulnerable children in Ethiopia, Development in Practice no.3, May.

De Haan, A. (1999) Livelihoods and Poverty: The Role of Migration - A Critical Review of the Migration Literature, Journal of Development Studies 36(2): 1-47.

De Lange, A. (2007) Child Labour Migration and Trafficking in Rural Burkina Faso, International Migration 45(2): 147-167.

Dobson, M. (2009) Unpacking Children in Migration Research, Children's Geographies 7:3, 355-360.

Dottridge, M. (2007) Collateral Damage: The Impact of Anti-Trafficking Measures on Human Rights around the World, Bangkok: GAATW.

Gebre, A. (2010) 'Migration Patterns of Children Exposed to Sexual Exploitation in Selected Zones of Amhara Region and Sub-Cities of Addis Ababa'. In Children on the Move in Ethiopia, papers presented for ESSSWA Seminar Series on Children, Addis Abababa, March 2010.

Gedlu, A. (2010) 'Child Labour in the Informal Sector: the Cae of Gulele Sub-city, Addis Ababa', in Children on the Move in Ethiopia, papers presented for ESSSWA Seminar Series on Children, Addis Abababa, March 2010.

Goody, E. (1982) Parenthood and Social Reproduction: Fostering and Occupational Roles in West Africa, Cambridge: Cambridge University Press.

Hashim, I.M. (2003) 'Child Migration: Pathological or Positive?', International Workshop on Migration and Poverty in West Africa, University of Sussex, UK. 
Hashim, I.M. (2005) 'Research Report on Children's Independent Migration from Northeastern to Central Ghana', Research Report from the Development Research Centre on Migration, Globalisation \& Poverty, University of Sussex, UK.

Hashim, I.M. and Thorsen, D. (2011) Child Migration in Africa, London: Zed Books.

Heissler, K. (2009) "No one comes on their own": The system of child labour migration in Bangladesh, Working Paper, Oxford, COMPAS.

http://www.compas.ox.ac.uk/publications/working-papers/wp-09-72/ . Accessed 07.11.11.

Heissler, K. (2010) Migrating with Honor: Sites of Agency and Power in Child's Labor Migration in Bangladesh. In: MO Ensor and E. Gozdziak (eds.) Children and Migration: At the Crossroads of Resiliency and Vulnerability. Basingstoke, Hampshire: Palgrave Macmillan.

Heissler, K. (forthcoming), 'Rethinking "trafficking" in children's migratory processes: The role of social networks in child labour migration in Bangladesh', Children's Geographies.

Heissler, K. and Porter, C. (forthcoming) ‘Know Your Place: Ethiopian Children's Contributions to the Household Economy', European Journal of Development Research.

Howard, N.P. (2008) Independent Child Migration in Southern Benin: An Ethnographic Challenge to the "Pathological" Paradigm, Saarbrücken: VDM Verlag \& Co.

Huijsmans, R. (2006) Children, Childhood and Migration, Working Papers Series No. 427, Institute of Social Studies, The Hague. http://www.intra1.iss.nl/iss/profile/AA7238 . Accessed 07.11.11. 
Huijsmans, R. (2008) Children Working Beyond their Localities: Lao Children Working in Thailand, Childhood 15(3): 331-53.

Huijsmans, R. (2011) 'Child Migration and Questions of Agency', Development and Change, 42(5): 1307-1321.

Huysmans, J. (2006) The Politics of Insecurity: Fear, Migration and Asylum in the EU, Routledge: London.

Kempadoo, K. (2005) From Moral Panic to Global Justice: Changing Perspectives on Trafficking. In Kempadoo, K. Sanghera, J. and Pattanaik, B. (eds.) Trafficking and Prostitution Reconsidered: New Perspectives on Migration, Sex Work and Human Rights, Boulder: Paradigm.

Leinaweaver, J. (2007) Choosing to Move: Child Agency on Peru's Margins, Childhood 14.3: 375-92.

Leinaweaver, J. (2008) The Circulation of Children: Kinship, Adoption, and Morality in Andean Peru. Durham, NC : Duke University Press.

Mann, G. (2001) Networks of Support: A Literature Review of Care Issues for Separated Children. Stockholm: Save the Children Sweden.

MOFED (2010) Ethiopia: Growth and Transformation Plan (GTP) 2010/11-2014/15), Addis Ababa: Ministry of Finance and Economic Development.

Ní Laoire, C., Capena-Méndez, F., Tyrrell, N. and White, A. (2011) Childhood and Migration in Europe: Portraits of Mobility, Identity and Belonging in Contemporary Ireland. Farnham and Burlington, VT: Ashgate. 
O'Connell Davidson, J. and Farrow, C. (2007) Child Migration and the Construction of Vulnerability, Gothenburg, Save the Children Sweden.

Punch, S. (2007) Negotiating Migrant Identities: Young People in Bolivia and Argentina, Children's Geographies 5: 1-2 95-112(18).

Rain, D. (1999) Eaters Of The Dry Season: Circular Labor Migration In The West African Sahel, Boulder: Westview Press.

Scalettaris, G. (2007) Refugee Studies and the International Refugee Regime: A Reflection on a Desirable Separation, Refugee Survey Quarterly, 26:3.

Sheller, M. and Urry, J. (2006) The New Mobilities Paradigm, Environment and Planning, A 38(2): 207-26.

Tafere, Y. and Camfield, L. (2009) 'Community Understandings of Children's Transitions in Ethiopia: Possible Implications for Life Course Poverty', Working Paper No. 41, Oxford. http://www.younglives.org.uk/our-publications/working-papers/communityunderstandings-of-children2019s-transitions-in-ethiopia-possible-implications-for-lifecourse-poverty. Accessed 08.11.11.

Tegegne, T. and Asres, S. (2010) 'The Situation of Child Trafficking in Bahir Dar', in Children on the Move in Ethiopia, papers presented for ESSSWA Seminar Series on Children, Addis Abababa, March 2010.

Thorsen, D. (2007) "If Only I Get Enough Money for a Bicycle!" A Study of Child Migration Against a Backdrop of Exploitation and Trafficking in Burkina Faso', Occasional Paper, Centre for African Studies, University of Copenhagen.

UNICEF (2011), The State of the World's Children 2011: Adolescence - An Age of Opportunity, UNICEF: New York. 
UNITED NATIONS (2000), Protocol to Prevent, Suppress and Punish Trafficking in Persons, Especially Women and Children, supplementing the UN Convention against Transnational Organized Crime, Vienna: UNODC.

Van Vleet, K. (2008) Performing Kinship: Narrative, Gender, and the Intimacies of Power in the Andes, Austin: University of Texas Press.

Verhoef, H. (2005) A Child Has Many Mothers: Views of Child Fostering in Northwestern Cameroon, Childhood 2005(12): 369.

Walmsley, E. (2008) Raised by Another Mother: Informal Fostering and Kinship Ambiguities in Northwest Ecuador, Journal of Latin American and Caribbean Anthropology 13(1):168-195.

Weisner, T.S. And Gallimore. R. (1977) My Brother's Keeper: Child and Sibling Caretaking, Current Anthropology, 18, 169-190.

Whitehead, A., Hashim, I.M. and Iversen, V. (2007) 'Child Migration, Child Agency and Inter-generational Relations in Africa and South Asia', Working Paper T24, Working Paper Series, Migration DRC, Brighton.

http://www.childmigration.net/MigrationDRC Whitehead Hashim Iversen 07. Accessed 01.08.11.

Woldehanna, T. (2010), Productive Safety Net Program and Children's Time Use Between Work and Schooling in Ethiopia, Child Welfare in Developing Countries, Part II, 157-209.

Woldehanna, T., Gudisa, R, Tafere, Y and Pankhurst, A. (2011) Understanding Changes in the Lives of Poor Children: Initial findings from Ethiopia. Young Lives Round 3 Survey Report. 
http://www.younglives.org.uk/files/presentations/woldehanna ethiopiaround3surveyoverview 27sept2011. Accessed 10.11.11.

Young Lives (2009) The Impact of Parental Death on Child Outcomes: Evidence from Ethiopia, Young Lives Policy Brief 7. Oxford. http://www.younglives.org.uk/files/policypapers/the-impact-of-parental-death-on-child-outcomes-evidence-from-ethiopia.

Accessed 09.11.11.

Young Lives (2009b) Focus on Children: Breaking the Cycle of Poverty, Young Lives Conference Report. Oxford: Young Lives. http://www.younglives.org.uk/what-wedo/news-and-events/events-archive/young-lives-international-conference-2009. Accessed 09.11.11. 